\title{
Designed in Shenzhen: Shanzhai Manufacturing and Maker Entrepreneurs
}

\author{
Silvia Lindtner \\ University of Michigan \\ Ann Arbor, MI-48104 \\ lindtner@umich.edu
}

\author{
Anna Greenspan \\ NYU Shanghai \\ Shanghai, China-200122 \\ ag158@nyu.edu
}

\author{
David Li \\ Hacked Matter \\ Shanghai, China-200050 \\ david.li@hackedmatter.com
}

\begin{abstract}
We draw from long-term research in Shenzhen, a manufacturing hub in the South of China, to critically examine the role of participation in the contemporary discourse around maker culture. In lowering the barriers of technological production, "making" is being envisioned as a new site of entrepreneurship, economic growth and innovation. Our research shows how the city of Shenzhen is figuring as a key site in implementing this vision. In this paper, we explore the "making of Shenzhen" as the "Silicon Valley for hardware." We examine, in particular, how maker-entrepreneurs are drawn to processes of design and open sharing central to the manufacturing culture of Shenzhen, challenging conceptual binaries of design as a creative process versus manufacturing as its numb execution. Drawing from the legacy of participatory design and critical computing, the paper examines the social, material, and economic conditions that underlie the growing relationship between contemporary maker culture and the concomitant remake of Shenzhen.
\end{abstract}

\section{Author Keywords}

Maker culture, industrial production, manufacturing, participation, open source, DIY, China, , Shanzhai.

\section{ACM Classification Keywords}

H.5.m. Information interfaces and presentation (e.g., HCI): Miscellaneous.

\section{INTRODUCTION}

Critical scholarship of computing has long been committed to questioning the apparently strict separation between production and consumption, design and use. One of the most widely known and impactful approaches has been participatory design (PD). With roots in the Scandinavian labor movement in the 1970s, PD emerged alongside outsourcing, automation and the introduction of Information Technology into the workplace. PD sought to intervene in these processes, promoting the view that the user and the larger social context and surrounding material culture should be central to considerations and processes of

Copyright $(2015$ is held by the author(s). Publication rights licensed to Aarhus University and ACM

5th Decennial Aarhus Conference on Critical Alternatives August 17 - 21, 2015, Aarhus Denmark

DOI: $\underline{\text { http://dx.doi.org/10.7146/aahcc.v1i1.21265 }}$ design $[3,6,7,27,43]$. Drawing on this work, this paper argues that contemporary processes of technology design necessarily include the place and culture of production.

Today, PD's call for involvement of users into the design process is not only accepted in popular design approaches such as human-centered design, but has also morphed into a business strategy. Bannon and Ehn, for instance, document the ways in which corporations promote the view that users and designers co-create value [3]. They illustrate the expansion of "a managerial version of user driven design" rooted in "market-oriented business models removed from PD concerns" [3]. Closed company innovation has increasingly given way to "open innovation" models, where creativity, knowledge and expertise of users are leveraged for company profit.

PD's call for critical intervention is further complicated by the recent flurry of devices and tools ranging from social media apps to smart devices (or Internet of Things), whose value depends on the participation of users. While companies like Facebook mine behavior data online to sell it back to its users in the form of ads, newer companies like Misfit see the value of smart wearables in the sensitive data their users generate and share by wearing the device while sleeping, walking, driving, working, exercising, etc. Advocates of the "maker movement" also celebrate a new formulation of user participation. By providing the tools, machines and platforms that enable people to make their own technologies, "makers" hope to turn passive consumers into active participants not only in technological design, but also in economic processes and civic matters (for prior work see e.g. [2, 18, 25, 31, 33, 39, 40, 45]. Open hardware platforms like the Arduino and affordable CNC machines like the $3 \mathrm{D}$ printer are envisioned to enable otherwise passive consumers to produce their own devices, tools, and eventually machines.

This contemporary promotion of "participatory production" [3] has critical gaps, as a return to the original concerns central to participatory design makes clear. Although design has been opened up to include and benefit from the participation of users (as elaborated above), the question of who is considered a legitimate participant in the design process has remained fairly limited. In particular, there is often an unspoken separation between what happens in the design studio, makerspace, hardware incubator or home office (the site of ideation, co-creation, appropriation, and 
day-to-day use) and what happens on the factory floor (the site of manufacture, production, and wage labor). The "human" in human-centered design, the "participant" in participatory design, and the "maker" who advocates the "democraticization" of production concentrates on the designer-user/producer-consumer relationship, but rarely on the relationship to the factory worker, producer, mechanical engineer, and so on. This is particularly ironic considering PD's original concern to intervene in processes of outsourcing, deskilling of labor, and the re-organization of work [3, 6, 7]. The central argument of what follows is that 'participation' in the design process does not only include the social context of the end user, but also, crucially, the material, socio-economic and cultural context of production. This paper demonstrates this by focusing on the manufacturing hub of Shenzhen, China, as a crucial agent in much of the design and creation of contemporary technology.

"Making" is often celebrated as a method that might revitalize industrial production in Western knowledge economies, e.g. [1]. In reality, this is not a straight-forward or easy process. Many hardware start-ups face difficulties in transitioning from hobby to professional making and manufacturing $[16,49]$. A number of businesses have tried to capitalize on these difficulties by providing makerentrepreneurs with an access to manufacturing in China. Take, for instance, Highway1, a hardware incubator in San Francisco, which promises start-ups a smooth transition into mass manufacturing without having to spend substantial amounts of time at their China-based manufacturing sites. Here, engaging with manufacturing expertise is rendered a problem space and an inconvenient hurdle for designers, makers and start-ups. Implicit in this approach is a widespread conception of technology production, which splits manufacturing and design along geographical lines; in which technology is conceived and designed in the West, and then manufactured in low-wage regions with loose regulatory environments. The evidence of this idea of design is emblazoned on the iPhone: "Designed by Apple in California. Assembled in China." Designers, here, are understood as the agents, with their ideas being executed elsewhere. In its most extreme formulation this division corresponds to a Cartesian inspired 'mind-body dualism' in which an active rational mind in the West guides a passive, inert body in the so-called developing world.

In this paper, we build on prior work that has begun challenge simplistic binaries of design-production, examining processes and cultures of design, making, and repair in regions outside of the United States and Europe [3, 23, 25, 39]. Drawing from research with mobile repair workers in rural Namibia, for example, Jackson et al. [25] focus on mundane sites of repair, breakdown and reuse as important, but often neglected sites of design. In engaging with these often overlooked places, commonly thought of as technologically, economically and socially "behind," scholars have argued for an approach that challenges models of technological production in which design and innovation are seen to emerge predominantly from global epicenters in the West (e.g. Silicon Valley) [2, 3, 13, 23, 25, 38].

Our work builds upon this research, by taking seriously manufacturing as site of expertise, design and creative work. We draw from long-term ethnographic research with factories, makers, and hardware start-ups in Shenzhen, a global hub of electronic manufacturing located in Southern China. In this paper, we analyze the social, technological, and economic processes of manufacturing in Shenzhen, rooted in a culture of tinkering and open source production that has evolved in the shadows of global outsourcing and large-scale contract manufacturing. We demonstrate that a growing number of maker entrepreneurs have begun to intersect with this manufacturing ecosystem, experimenting with modes of design, production, and collaboration. Examining these intensifying collaborations enables a deeper and nuanced conceptualization of both design and of the ongoing transformation of Shenzhen.

\section{Shenzhen \& the maker movement}

In the last years, there has been a growing interest in the potential impact of a so-called "maker" approach to technological innovation, education, and economic growth [29]. "Making" is thought to enable a move from tinkering and play, to prototyping and entrepreneurship and, finally, to help revive industries and sites of manufacturing lost due to histories of outsourcing. Making is drawing investment from governments, venture capitalists, and corporations around the world. While the US government promotes digital fabrication and making as a way to return to the "made in America" brand (with the White House hosting its own Maker Faire) [33, 36], the European Union has introduced formal policies aimed at rebuilding manufacturing capacities and know-how in order to sustain their knowledge economies [15]. Large international corporations have also started to invest. In 2013, Intel introduced the Arduino compatible Galileo board; an "Intel inside" microcontroller platform aimed at branding Intel as a champion of the maker approach.

Our work challenges the dominant narratives of maker culture by critically investigating the relationship between making, designing, and manufacturing. We argue for a return to one of the most fundamental concerns of $\mathrm{PD}$, i.e. to foreground the expertise, tacit and situated knowledge of everyday work practice $[43,46]$. Our focus is on the ways in which the city of Shenzhen has emerged as a central player in the broader imaginary as making shifts from hobby to entrepreneurial practice. Shenzhen figures in the global maker imaginary as a "maker's dream city" or "the Silicon Valley for hardware," where visions of technological futures get implemented today. Until recently, few technology researchers and people in the broader IT media sector have paid much attention to Shenzhen. This began to change, when a growing number of "makers" 
traveled to the coastal metropolis to turn their ideas into end-consumer products. Well-known examples of these made-in-China devices are the virtual reality goggles Oculus Rift and the Pebble smart watch. In 2012, one of the first hardware incubator programs, HAXLR8R (now renamed as HAX), opened its offices in Shenzhen. Other investment programs such as Highway1, Bolt, and Dragon Innovation followed suit. Shenzhen draws not only makers and hardware start-ups, but also large corporations such as Intel, Texas Instruments, Huawei, and more. Intel, for instance, has invested 100 million USD in what the company calls the "China Technology Ecosystem" in Shenzhen [22]. Since 2013, the MIT Media Lab has organized tours for its students through Shenzhen's electronic markets and factories. In a recent blog post Joi Ito, head of the Media Lab, records his impressions, describing local factories as "willing and able to design and try all kinds of new processes to produce things that have never been manufactured before" [24].

How did Shenzhen, once known as a site of cheap and low quality production, become the place to be for contemporary hardware innovation? How have design processes, such as those that Ito speaks of, developed and fed into the culture of manufacturing that has emerged in the city over the past three decades? Who is considered a legitimate participant and what sites of expertise and design are rendered invisible?

The findings presented in this paper challenge the common binary of "made in China" versus "designed in California" that inherently associates the West with creativity and innovation and China with low quality production. We argue that what we witness in Shenzhen today has an important impact on the relationship between making, manufacturing and design. This paper contributes by shedding light on a situated practice of design, prototyping and ideation that emerges from within manufacturing. The paper, thus, provides new insights into histories and cultures of professional design and making that have emerged outside of more familiar IT hubs such as Silicon Valley [41, 47]. Our aim is to foster an engagement with mundane sites of contemporary industrial production - like Shenzhen - in order to advance a critical inquiry of design, maker production, global processes of technology work and labor, and participation.

\section{METHODS \& APPROACH}

We draw from long-term research about technology production in China in order to examine the cultural and technological processes that unfold at the intersection of design and manufacturing. This includes in-depth ethnographic research conducted over 5 years, hands-on participation in maker and manufacturing projects, and the hosting of a series of interdisciplinary workshops and conferences that brought together scholars and practitioners concerned with making and manufacturing. Ethnographic research conducted by the first author included long-term participant observation in five hackerspaces and at over thirty maker-related events such as Maker Faires, Maker Carnivals, Hackathons, Barcamps, and Arduino workshops across the cities of Shanghai, Beijing, and Shenzhen, as well as several months of ethnographic fieldwork at a hardware incubator in Shenzhen, following the day-to-day workings of ten start-ups and their journeys of moving from idea into production. Participant observation at hackerspaces included joining daily affairs such as prototyping, space management, member meet-ups, open houses, and the organization of workshops. The research at the hardware incubator included daily observations at the office space as well as accompanying start-ups during sourcing, prototyping, and manufacturing.

Between 2012 and 2014, we made numerous trips to Shenzhen to focus on the history and culture of the region's local manufacturing industry. We hosted a series of handson workshops and intensive research trips in Shanghai and Shenzhen (in total 5 over the duration of two years). These events enabled us to bring together an interdisciplinary network of 120 scholars, makers and industry partners from China, the United States, South-East Asia, and Europe concerned with "making." Backgrounds of our participants spanned the fields of HCI, the arts, design, engineering, manufacturing, science fiction writing, and philosophy.

Throughout these events, we collated hundreds of hours of video and audio material of interviews, field visits, panel discussions, hands-on workshops and discussion sessions. In total, we conducted over 150 formal interviews with relevant stakeholders including makers, members and founders of hacker and maker spaces, organizers of maker related events, factory workers, owners, and managers, government officials and policy makers, employees in design firms and large IT corporations who were invested in making and manufacturing, artists and urban planners, entrepreneurs and investors. As common in ethnographic research, we prepared sets of interview questions, which we expanded and modified as we went along and identified emergent themes and new questions. We combined discourse analysis, situational analysis [11], and research through design $[5,51]$. Although we have interviewed people from a wide range of backgrounds, for the purposes of this paper, we draw on a subset of our interviews, which were conducted with people active in Shenzhen's manufacturing industry as well as those from the global maker scene who are intersecting with manufacturing. As many of our interviewees are public figures, we refer them, when they spoke in a public context (e.g. at workshops, conferences, Maker Faires, etc.), by their real names. We anonymized all informal conversations and interviewees who preferred not to be named.

Our research team comes from a mixed background including interaction design, HCI, cultural anthropology, China studies, urban studies, philosophy, entrepreneurship, and physical computing. This has proven to be effective in 
allowing an in-depth engagement with both the technological and social practices of making and manufacturing. All of us speak Mandarin Chinese (one of us is a native speaker and the other two have received formal language training for more than 5 years). Interviews were conducted in both English and Chinese. All formal interviews were professionally translated and transcribed.

\section{SHENZHEN: FROM OUTSOURCING TO SHANZHAI}

Shenzhen is a young city; the build up of its urban landscape dates back only 30 years ago, when a series of village collectives began to be transformed into one of the world's largest manufacturing hubs, e.g. [14, 34]. This was in part enabled by the implementation of a government policy that declared Shenzhen a Special Economic Zone (SEZ) [19, 30]. In 1979, when the SEZ policy went into effect, Shenzhen had a population of under 50000 , by 2010 it had morphed into a metropolis of over 10 million people ${ }^{1}$.

The growth of Shenzhen coincided with, and was propelled by, an outsourcing boom, which, to quote Lüthje et al., "emerged from the massive restructuring of the US information technology industry that began in the 1980s" [30]. Throughout this period, companies in the US and Europe moved their manufacturing facilities into low-cost regions of the so-called developing world. Shenzhen constituted a particularly attractive site; as an SEZ the barriers of entry for foreign corporations were significantly lowered, with a range of incentives including tax reductions, affordable rents and investments aimed at integrating science and industry with trade. The outsourcing of factories and manufacturing clusters radically reshaped the high tech districts of the United States. As a result, by the 1990s, with the rise of the "new economy," the IT industry was "no longer dominated by vertically integrated giant corporations such as IBM but rather was shaped along horizontal lines of specialized suppliers of key components such as computer chips, software, hardware disk drives, and graphic cards" [30].

With the gradual upgrade of technological and organizational skills in former low-cost assembly locations, a process of vertical re-integration began to take place. By the late 1990s, Taiwanese ODMs (original design manufacturing) such as Acer, HTC, Asus and Foxconn, which designed the manufactured product on behalf of their brand-name customers, started to develop substantial intellectual property rights on their own [30]. One particularly famous example is the ODM HTC that entered the market with its own branded cell phone. This shift began challenge the global leadership of established hightech economies.

\footnotetext{
${ }^{1}$ We can't do justice here to the complexity of Shenzhen's history and direct the reader to work by Mary Ann O'Donnell, Juan Du, Winnie Wong, Josephine Ho, Carolyn Cartier, and others [9, 14, $19,34,35,50]$.
}

As contract manufacturers grew in size, and began catering predominantly to large brands, a network of entrepreneurs saw an opportunity to establish themselves in the gaps of the global economy. A dense web of manufacturing businesses emerged in Shenzhen, catering towards less well-known or no-name clients with smaller quantities, who were not of interest to the larger players. This less formal manufacturing ecosystem (known as shanzhai 山寨 in Chinese) is comprised of a horizontal web of component producers, traders, design solution houses, vendors, and assembly lines. They operate through an informal social network and a culture of sharing that has much in common with the global maker movement (though largely motivated by necessity rather than countercultural ideals). We now turn, in greater detail, to this local manufacturing culture.

\section{Shanzhai 山寨}

Shanzhai translates into English as mountain stronghold or mountain fortress, and connotes an informal, outlaw tradition. The term has been in use in China for a long time and features most prominently in folk stories like the Shuihuzhuan (water margins) that tells the adventures of 108 rebels, who hide in the mountains and fight the establishment. Building on this common narrative, Jeffrey, describes shanzhai as the story of "outlaws who have gone away to the mountains, doing things within their own rules. There's an element of criminality about shanzhai, just the way that Robin Hood is a bit of an outlaw. But it's really about autonomy, independence, and very progressive survival techniques." [26].

Scholars speculate that the term was first applied to manufacturing in the 1950 s to describe small-scale familyrun factories in Hong Kong that produced cheap, low quality household items, in order to "mark their position outside the official economic order" [19]. They produced counterfeit products of well-known retail brands such as Gucci and Nike, and sold them in markets that would not buy the expensive originals. As electronic manufacturing migrated to Shenzhen the informal network of shanzhai manufacturing found a perfect product in the mobile phone. Shanzhai production includes not only copycat versions of the latest iPhone, but also new creations and innovations of phone design and functionality (see Figure 1).

Within China, shanzhai devices are catered towards lowincome migrant populations that could not afford more expensive branded products. Shanzhai phones have a strong global market, targeting low-income populations in India, Africa, and Latin America [20, 48]. As the shanzhai ecosystem matures, we are beginning to see the development of branded phones. Xiaomi (小米), to take but one example, is an affordable smart phone that comes with a chic design and makes use of sophisticated branding techniques. Although it grew by leveraging the shanzhai industry, Xiaomi is rarely associated with it. 


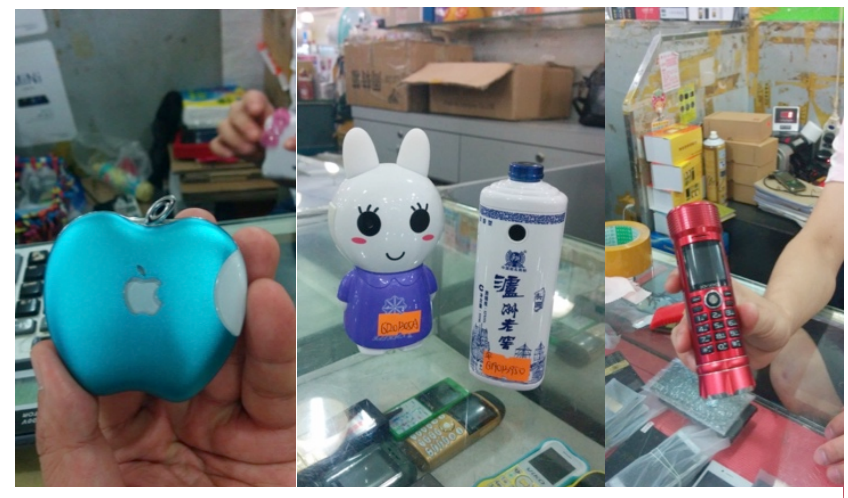

Figure 1. Examples of four shanzhai phones (from left to right): phone shaped as apple, phones shaped after children's toy and Chinese alcohol brand, phone that also functions as flashlight and radio. Photos taken by authors, 2012-2014.

Rather it has become widely accepted as a national phone brand that many Chinese are proud of.

While some people associate shanzhai with stealing and low quality goods [48], there is a growing endorsement of shanzhai as a prime example of Chinese grassroots creativity that has innovated an open source approach to manufacturing. One strong proponent is Bunnie Huang, who gained widespread recognition when he hacked the Xbox in 2003. In a series of blog posts, Huang details the workings of shanzhai as a unique "innovation ecosystem [that developed] with little Western influence, thanks to political, language, and cultural isolation" [21]. Huang here refers to a highly efficient manufacturing ecosystem that rests on principles of open sharing that are different from, but also compatible with, more familiar open sharing cultures.

Shanzhai is neither straightforward counterculture nor prosystem. As a multi-billion USD industry, it is deeply embedded in contemporary modes of capitalist production. At the same time, with its roots in and ongoing practices of piracy and open sharing, shanzhai challenges any inherent link made between technological innovation and the tools, instruments, and value systems of proprietary, corporate research and development. As Jeffrey and Shaowen Bardzell argue, analysis that upholds the strict boundaries between critical design and affirmative design; resistance culture and capitalist culture is often too simplistic [4].

Shanzhai producers are acutely aware of the global market economy, and have developed incisive and canny strategies to negotiate, subvert, criticize, ironize, and profit from it [19]. The early and affordable shanzhai versions of the smart phone, for instance, were designed for customer segments that could not afford the expensive and branded phones on the market. Shanzhai disrupted who gets to decide over new markets, customers, and how tech business was to be done. In other words, issues of concern in critical and reflective design practice - such as "passivity," "reinforcing the status-quo," "illusion of choice" [4] - are as salient in shanzhai production as they are in conceptual design. It is particularly ironic, then, that while open hardware hacking in the West is celebrated as enabler of future innovation, the open manufacturing mechanism of shanzhai is often denounced as holding China back on its modernization path due to its lack of principles and norms such as the international copyright law [19]. In the next section we describe in greater detail the particularities of shanzhai's open production.

\section{OPEN MANUFACTURING: GONGBAN \& GONGMO}

During our research in Shenzhen, we met and interviewed many different players in shanzhai production ranging from component producers, vendors, traders, assembly, and design solution houses. One consistent element that we found to be at the core of shanzhai was the production of so-called “public boards," called gongban (公版) in Chinese; production-ready boards designed for endconsumer electronics as well as industry applications. Gongban are typically produced in independent design houses that link the component producers (e.g. a chip manufacturer) and the factories that assemble the different parts into phones, tablets, smart watches, medical devices, and so on.

During our research, we followed closely the process of one of the region's largest distributers and their internal design house that produces about 130 gongban per year. The design house does not sell any of these reference boards, but rather gives them out to potential customers for free, alongside a list of components that go into making the board as well as the design schematics. The company makes money by selling the components that go into the boards. As such, it is in their interest to support as many companies as possible to come up with creative "skins" and "shells" (called gongmo in Chinese) that are compatible with their boards. Their customers, then, take a gongban of their liking as is or build on top of it. The boards are designed so that the same board can go into many different casings: e.g. one board can make many different smart watches or many differently designed mobile phones. Since 2010, years before Pebble Watch or the Apple Watch made news, thirty some companies in Shenzhen were shipping their own smart watches based on this open production mechanism (see Figure 2).

The gongban public board functions like an advanced version of an open source hardware platform such as the Arduino, yet differs in that it constitutes a bridge into manufacturing. "We call this shanzhai in Shenzhen. It's a mass production artwork," explained Larry Ma (anonymized), the head of the aforementioned distributor's design house. To Larry Ma, there is no question that shanzhai is different from simple copycat. "First, shanzhai needs creativity: it is something only a person with a quick reaction who knows the industry chain very well can do. 


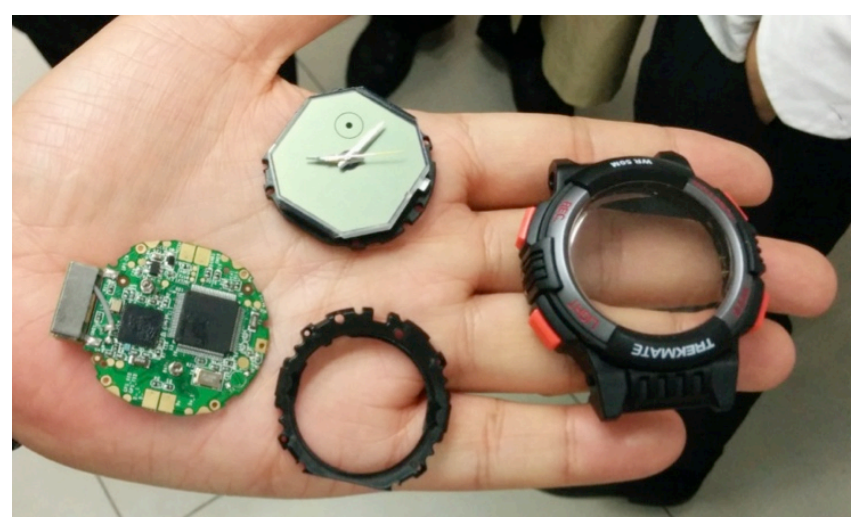

Figure 2. Gongban (public/open board) and Gongmo (public/open casing) of a smart watch, Shenzhen, China. Photo taken by authors, April 2014.

Shanzhai makers are asking themselves what the normal people will need next... It is very important that you are very familiar with the upstream and downstream industry chain. And there is a kind of hunger. These three elements together make it an art work... it's about being hungry for the future."

Larry Ma's R\&D unit is one of many corporate entities in the shanzhai ecosystem that have grown over the years into substantial businesses. This growth has occurred outside the traditional IP regime, using an open manufacturing ecosystem rooted in open reference boards, and a culture in which the bill of materials (a list of all the materials that goes into making a particular device, something that a company like Apple keeps strictly closed) is shared. This open culture of production has enabled local chip manufacturers such as Allwinner and Rockchip to compete with renowned international corporations like Intel. At the crux of this manufacturing process is their speed to market, driven by what Larry Ma describes as "hunger." In the shanzhai ecosystem, ideation, prototyping and design happen alongside the manufacturing process. Products are designed in relation to the demands of a fast changing market. Rather than spending months or years deliberating over the next big hit, shanzhai builds on existing platforms and processes, iterating in small steps. In this way, shanzhai brings new products to the market with remarkable speed. In Shenzhen, cellphones can go from conceptual designs to production-ready in 29 days. Products are market-tested directly by throwing small batches of several thousand pieces of a given product into the market. If there is demand and they sell quickly, more will be produced. There is a commitment to never building from scratch (an approach that is shared by the open source community). Prototyping and consumer testing occur rapidly and alongside the manufacturing iteration process, rather than occurring beforehand (where it is commonly placed in Westerncentric design models).

A particular social dynamic is crucial to this design in manufacturing process. Personal and business lives blend, and important decisions with regards to investment, release dates, and collaboration partners are often made over informal dinner meet-ups and weekend gatherings. These social connections are central to getting business done in Shenzhen, as we discuss in greater detail in the next section. Many of our interlocutors saw themselves as belonging to a grassroots community and maintained that it was the mutual support of Shenzhen's open manufacturing culture that enabled their competitive advantage.

\section{MAKING IT IN SHENZHEN}

Shenzhen's population comes from elsewhere. More than $95 \%$ of the city's population is migrants. Shenzhen's technology sector grew from the intersection of two early flows. The first were technological entrepreneurs from Taiwan, involved in the early chip industry, who sought to take advantage of China's economic opening and it's initial experiments with SEZ's. This stream of capital cross-fed into a giant internal movement throughout the Mainland, in which a vast 'floating population', freed from the controls of the command economy, poured into the coastal cities looking for work. This dynamic is still very much at work today. In the summer of 2014, Foxconn was reported to be recruiting 100000 workers to build the iPhone 6 .

It is not only the promise of a better income, but the hopes for a different future that motivate hundreds of thousands of migrant workers every year to seek employment in Shenzhen, often far away from their home towns and families, sending back remittances. Though, as is widely reported, there is an issue of sweatshop labor in Shenzhen, many of the people we met during our research promote Shenzhen as full of opportunities, a dream city, a place where "you can make it" in China today. Violet Su, for instance, worked her way up from a part-time job to personal assistant to Seeed Studio"s CEO "Shenzhen is a good place to live," she says. "If you go to another city, people treat you like outsiders. But here everyone belongs. It's like as if everyone was born here. When I first came to Shenzhen I really liked one of the city's slogan that decorated the bus: 'When you come to Shenzhen, you are a local person."

Many who enter the shanzhai ecosystem do not come from privileged socio-economic backgrounds. Take, for instance, Ye Wang (anonymized), the manager of a shanzhai tablet company. Wang is one of the few, who "made it." His company has revenue of several million USD a year, shipping tablets to South America, Eastern Europe, Russia, and the United States. Wang originally came to Shenzhen at the urging of a relative who was working at the Chinese car manufacturer BYD (Build Your Dream) and who helped

\footnotetext{
${ }^{2}$ Seeed Studio is a Chinese hardware facilitator that sells open hardware products and educational kits, and connects makers driven to move from prototyping into production with Shenzhen's manufacturing ecosystem. www.seeedstudio.com
} 
Wang to get a corporate scholarship that funded his college education. After college, Wang entered what he calls "the shanzhai community." He made a name for himself by leading a development team that produced one of the first copycat versions of the Apple iPad. The localized, slightly altered version of the tablet was introduced into the Chinese market before Apple had officially released the iPad in the United States. This did not go by unnoticed by bigger players in the shanzhai ecosystem. Wang explained how, once one has gained trust and made a name for themselves, it is easy to find partners who are willing to freely share resources: "Shenzhen is working just like this. You can understand it as crowdfunding. It works differently from crowdfunding via online social networking ... you must be firmly settled in the industry, be recognized, have a good personality... Everybody in the industry chain gives you things for free, all the materials, and only when you have sold your product, you do the bills [and pay back]."

Wang, here, describes an important funding mechanism that enables people who lack the financial resources to nevertheless receive support from within the larger shanzhai network. People become part of this social network by participating in both informal face-to-face gatherings (over dinner, lunch, at the manufacturing site) and networking via mobile social media platforms such as Wechat (www.wechat.cn). Much of the offline activity takes place over alcohol-infused meals, KTV bars and massage parlors, establishments that are frequented by a largely male clientele, (all of which speaks to a strong gender hierarchy that infuses shanzhai culture). People in shanzhai think of themselves as driven and hard working, committed to improving their standard of living and to make money. Many considered the level of entrepreneurial possibilities unique to Shenzhen: "there is no other place like this in China. Here you find a lot of opportunities, you can become yourself, you can realize your dream, you can make a story out of your life."

Shanzhai production is fast and nimble mostly due to this unique social fabric through which decisions about new products, design and pricing are made collaboratively. This process entails people to be "on 24/7." Every personal interaction, no matter if offline or online, is also about furthering a collective goal: the expansion and spread of business opportunities, the discovery of niche markets and the distillation of new mechanisms that will generate additional sales. In this way shanzhai production culture is not dissimilar from Silicon Valley, with its male dominated management and entrepreneurial leadership, hard-driven work ethic and peer pressure, all of which forms a closeknit community of informal socializing and information sharing [41].

\section{MAKERS IN SHENZHEN}

In the last few years, Shenzhen has begun to draw yet another wave of migrants - mobile elites such as tech entrepreneurs, hackers, makers, geeks and artists, who are drawn to the city's abundance of materials and the production processes located here. For many of these newcomers the first stop in Shenzhen are the markets of Huaqiangbei (华强北), a 15-by-15-city block area, filled with large department store buildings. Each mall contains a labyrinth of stalls spread over several floors (see Figure 3). Malls specialize in everything from basic components such as LEDs, resistors, buttons, capacitors, wires, and boards to products such as laptops, phones, security cameras, etc. For makers, the markets provide immediate access to tools, components and expertise. Ian Lesnet from Dangerous Prototypes, a company that sells open hardware kits, describes the lure of Huaqiangbei and Shenzhen as a whole:

"The wonderful thing about Shenzhen is that we have both horizontal and vertical integration. In Huaqiangbei, you can buy components. Go a little bit further out, people sell circuit boards. A little bit further out, there are people who manufacture things and attach components to circuit boards. So you can actually have something built. And a little further out there are people who make product cases. A little further out you have garages with large-format printers who make labels for your products and a little further out they recycle it back down again. So you can build something, design it entirely, have it manufactured, sell it, and then break it down its components and recycle it back into the center of the markets. You have all the skills and all the people who can do that and they are all here in one place. And that's what's really enticing about Shenzhen."

"Living in Shenzhen is like living in a city-size techshop," echoes Zach Smith, one of the co-founders of the 3D printer Makerbot. Smith first came to Shenzhen when Makerbot started to collaborate with a local manufacturing business. Since then he has spent many years working and living in the city and has learnt to adapt to what he calls Shenzhen's "native design language." "If you come to Shenzhen, you are going to take your American design language and you

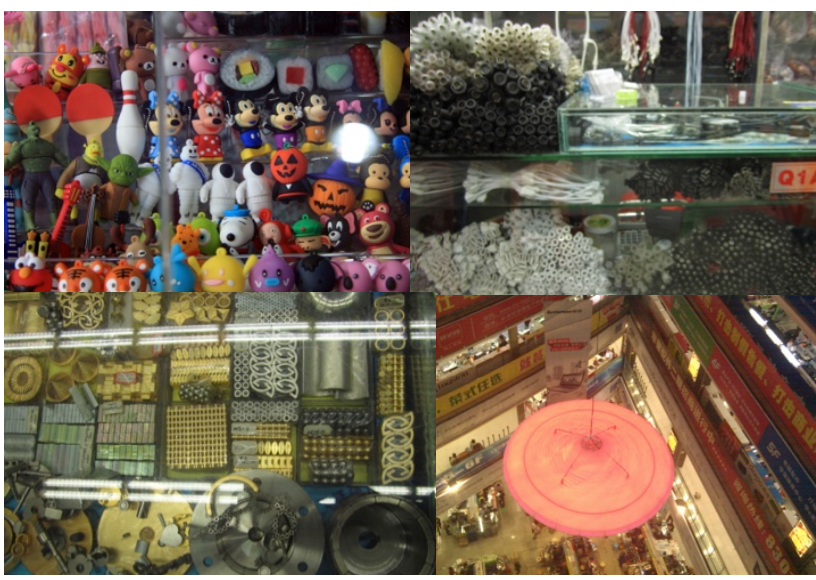

Figure 3. Huaqiangbei markets (upper left to bottom right): USB sticks shaped as plastic figurines, stacks of wires, assortment of magnets, department store building view from the top. 
are going to have to translate it," Smith explains. "If you are out here you can start to learn that local design language, and start using it in your own designs... It helps you make designs that are easier to manufacture, because you are not substituting a bunch of stuff... People out here can build their designs in this native way. As you go and meet with manufacturers you understand their design process, how they want to build things, or what they are capable of building. This changes the way you want to do your design, because as a designer, if you are a good designer, you are going to try and adapt to the techniques instead of making the techniques adapt to you."

What Smith describes here was something many of the makers we interviewed experienced; transforming their designs through interactions with factories, engineering processes, machines and materials. Manufacturers and makers work together to prototype, test materials and functionality, continuously altering everything from the shapes of product casings to PCB design (Printed Circuit Board). Together, they iterate and shape the design of the final product through a process that typically spans several months of frequent often-weekly meetings. Take, for instance, maker entrepreneur Amanda Williams, one of the few women active in the scene. She has been working closely with several different manufacturing units in Shenzhen during the process of designing an interactive lamp. Williams reflects on these collaborations as follows: "sometimes you find out from a factory that this won't work or that won't work, or you can't use this size because you need a certain amount of wall thickness or this material's gonna break... working with the factories, we understand how to modify our design, in order to make it better for mass manufacturing."

Makers working in Shenzhen are brought closer to the tactility that lies at the heart of hardware design. In molding their visions whilst enmeshed - rather than removed from the context of manufacturing, their designs become tuned to the materiality of the hardware, modulating their visions

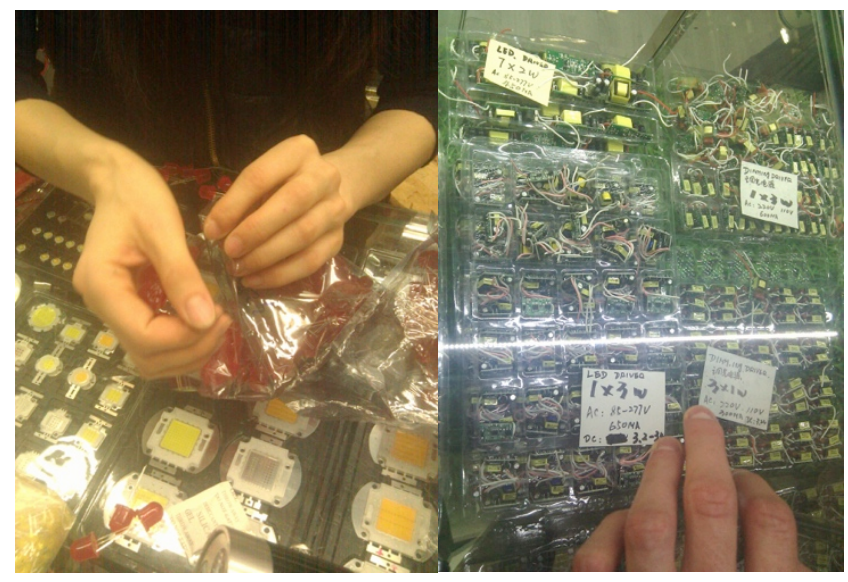

Figure 4. in Huaqiangbei: makers getting a "feel" for different components. Photos by first author, 2013. through bodily reactions to the size of a button or the feel of a knob, as Ian Lesnet elaborates: "When you design electronics, it's not just an engineering problem. It's a design process. Being able to just walk into Huaqiangbei, touch buttons, push them, be like, 'Oh, this one is weak. This one is strong.' Choosing things. Holding things. Get this amount of knowledge that you don't get sitting at a computer sitting somewhere else in the world" (see Figure 4). Many agreed that this tacit and embedded learning had become central to their design process and was something they learned only after they had arrived in Shenzhen. "In school, they don't teach you DFM, design for manufacturing, at all," says Antonio Belmontes from Helios Bikes, "the factory helps us bring our ideas down to design for manufacturing. They also help you save money. Especially when you approach them during the design process."

What draws tech entrepreneurs, makers and designers to Shenzhen is that phases of ideation, design, market testing, and industrial production evolve together in an iterative process (as opposed to design practices in which ideation and prototyping are thought of as phases that proceed and then guide processes of execution). What emerges is a tactile and deeply embodied design practice that requires close connections with both materials and the local skillsets that many describe as a highly professionalized form of making in action. John Seely Brown, former director of Xerox Park, during a visit to Shenzhen, reflected upon this process by speaking of tacit versus explicit knowledge. "What you are really doing," he said speaking of hardware production in Shenzhen, "is modulating a conversation between your tools and the materials your are working on for some end result. And you are overseeing that dance in its own right."

\section{SEEED STUDIO \& THE 2014 SHENZHEN MAKER FAIRE}

Much of what we see with regards to maker entrepreneurialism in Shenzhen today goes back to the early efforts of Seeed Studio, a Chinese hardware facilitator that connects Shenzhen's world of manufacturing with the global maker scene. Seeed Studio was founded in 2008 by the then 26-year old Eric Pan (潘浩) and grew quickly from a two-people start-up into a successful business that now has more than 10 Million USD annual revenue and over 200 employees. Seeed Studio sells hardware kits, microcontroller platforms, and custom-made printed circuit boards to makers. It also provides highly personalized services. One of Seeed Studio's core businesses is to enable maker start-ups to move from an idea to mass production by identifying what Eric Pan calls "pain points"-moments of transition, where a company lacks the knowledge of how to scale up. Seeed Studio products have gained reputation worldwide. They are offered for purchase online, on makerspecific platforms, and in mainstream retailers in the US. When HAXLR8R opened its doors as one of the first hardware incubator programs in Shenzhen in 2012 it was with the help and in the offices of Seeed Studio. 


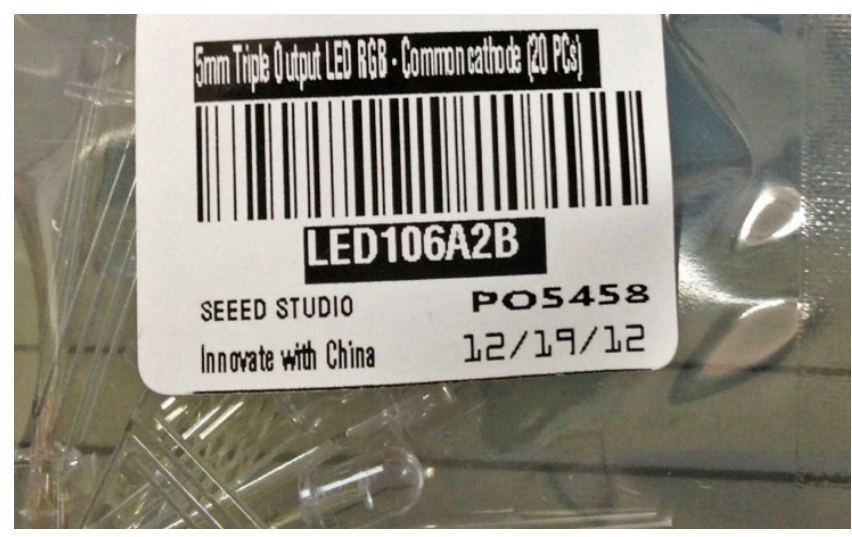

Figure 5. "Innovate with China," product label by Seed Studio.

Eric Pan has become an influential voice of China's maker scene eager to demonstrate that "made in China" can mean something more than just copycats and cheap labor. The first thing one reads, when entering the offices of Seeed Studio, is the tagline "innovate with China," painted on a large mural wall. A pun on the "made in China" brand, it is also the label that adorns Seeed Studio products (see Figure 5). "When I came to the US in 2010, people there knew us and liked our products, but nobody wanted to believe that we are a Chinese company," Pan recalls, "nobody had thought that cool and innovative products could come of China. That's why, ever since, we have been using 'innovate with China' on our product labels to demonstrate that manufacturing in China can mean 'partnership' and innovation instead of cheap labor and low quality."

"Innovate with China" was also the slogan of China's first featured Maker Faire that took place in April 2014, organized and hosted by Seeed Studio. The Maker Faire constituted an opportune moment for Seeed Studio to demonstrate its vision of China's creative role in the world of making and manufacturing. People who attended the Maker Faire were well-known figures in the maker community, and included amongst others Dale Dougherty, founder of MAKE magazine, Chris Anderson, who authored the book Makers, Tom Igoe who co-founded Arduino, Jay Melican who carries the informal title "Intel's Maker Czar," Eri Gentry from BioCurious, Vincent Tong and Jack Lin from Foxconn.

The talks and presentations at the Shenzhen Maker Faire were wrapped between two keynote speeches: Dale Dougherty, considered by many to be the founding father of the US maker movement, gave the opening speech, while Vincent Tong and Jack Lin (林志联) from Foxconn, gave the closing plenary. Dougherty, in his talk, focused on the creativity that lies in making one thing. He emphasized the culture of hobbyist creation and tinkering that went into the early stages of development of the first Apple computer, and described making as an adventure where the outcomes are uncertain. Tong and Lin, on the other hand, talked about the opportunities and challenges that lie in scaling up, moving from making one thing to making hundreds of thousands or millions of things. While Dougherty emphasized processes of tinkering and play, Tong and Lin focused on the role of design in the professionalized manufacturing process, or as Lin put it: "the process of making just one thing is very different from continuous production. It requires cross-disciplinary work. Hardware is different from the Internet. You need to think about design from the beginning. Design is central to all steps of the process of manufacturing including differentiation, customization, standardization... You also need to design for future manufacturing, for the next assembly you need to think about this from the beginning of the design process."

The Shenzhen Maker Faire was Dougherty's first visit to China. When we interviewed Dougherty during his visit, he reflected on the differences of making in the US and in China. "It's an indeterminate problem of 'how do I get this made?" he said speaking of the difficulties many hobbyist and professional makers face in the US, "where should I go to find the parts?" Makerspaces address part of the issue, he further elaborated, but scaling up was almost impossible: "They don't necessarily have the context, skill sets or knowledge to make. Even, "What are the right things to make or not make at all?" Part of it is that American manufacturing is geared to large companies, and so those interfaces aren't there for a small company." Dougherty, here, counters the overly euphoric narratives that view making as enabling an easy return to the "made in America" brand. "I see this as an information problem," he says "you might find out while being here that if you manufacture it this way, you should have designed it differently.'”

In Shenzhen, design on the factory floor is not unique to shanzhai, as those involved in the process know well. For instance, what transpired from a couple of visits to a big contract manufacturer (anonymized), even companies like Apple have their designers and engineers (just like maker entrepreneurs) work side by side with the designers and engineers at the factory, iterating together until the very last minute, when the product is frozen for release. This is in contrast to a common perception of Apple as the creator who outsources to the cheap labor provided by the manufacturer.

\section{DISCUSSION}

"Apple computers are this really big example. Designed in California, made in Shenzhen. We pride ourselves on design and we don't have to do that other work. Remember the paperless office. Things would just be designed on computers and then made. It was almost like we didn't need that dirty world near us. It could be in China... But physical things have properties that speak to us intuitively that we cannot just analyze on a computer screen, no matter how much resolution we have. That's calling into question that split between designed here and made there. “ 
(Dale Dougherty, Interview with the authors, April 2014)

This paper sets out to question a prevailing myth of technological production in which design is separated from what Dougherty, here, calls the "dirty world" of manufacturing. It does so by focusing on the culture of open production and design that has developed in Shenzhen over the last 30 years. More specifically, our research has concentrated on how the ecosystem of shanzhai emerged alongside the more-well known processes of outsourcing and governmental policy that opened up the region to foreign investment.

In doing so, our work challenges some of the prevalent discourses and practice around making and its engagement, however implicit, with participatory design. Central to the early efforts of participatory design, and critical scholarship of computing more broadly, has been an emphasis on the user and a desire to empower those who might have less say in technological production. Prominent figures of the maker movement have turned this call for individual empowerment into a powerful business strategy, e.g. [1]. Many maker kits and smart devices are marketed as educational in that they train their consumers to become producers themselves. Today, many users of digital fabrication tools and open hardware platforms are indeed producing a wide and rich variety of software code, electronic schematics, 3D designs, and so on. Committed to the culture and spirit of open source, many of these users also freely share their design contributions. Maker products, in this sense, function much like social media apps such as Facebook or virtual worlds like Second Life, in which the value of the product is significantly shaped by what people "make" with it [8]. While this certainly broadens the range and number of "participants" in the design of technology it is also subject to a growing critique of the "sharing economy," in which, "the labor of users, fans, and audiences is being put to work by firms" [45].

Moreover, digital fabrication tools such as the $3 \mathrm{D}$ printer or the CNC milling machine, which are envisioned to enable a broader audience to engage with processes of making, often keep the designer at arm's length from the kind of tacit knowledge necessarily involved in the manufacturingcentered design process we have described in this paper. While digital fabrication tools provide techniques for rapid prototyping in a design studio, they do not engage one with the situated and embodied processes of manufacturing on a large scale. What becomes increasingly clear from our engagement with Shenzhen is that, to repeat Dougherty's point stated above, "physical things have properties that speak to us intuitively that we cannot just analyze on a computer screen, no matter how much resolution we have." Thus, whilst the promotion of a return to hands-on making is pervasive ("everyone is a maker"), many of the software applications aimed at bringing designers into the production of hardware have been oriented around creating an abstract representation of production [17]. This separates the designer and maker from the embedded and embodied practice of production and the tacit knowledge that is essential to cultures of production documented here. Our aim is to challenge a mythic structure of technology innovation in which the "creative" work of design is highlighted, while the work of manufacturing remains at arms length. In short, we follow Bannon and Ehn in arguing, alongside the tradition of design anthropology, that the insights "from an understanding of material culture" be "more directly fed on to the practices of participatory design" [3]. A rigorous participatory design practice not only includes a deep engagement with the social context of users, but also with the material and social conditions of contemporary production.

Maker entrepreneurs who come to Shenzhen to turn visions of smart and networked devices into products are intersecting with these embedded and tactile processes of production. Indeed, it is the close proximity to the processes and materials of production that makes the city so enticing to makers. As we have shown in this paper, it is not just access to tools and machines, but a particular process of design that draws makers into Shenzhen; prototyping is part and parcel of fabrication, rather than preceding it; and testing and designing evolves through daily interactions with the workings of machines, materials, components, and tools. From the electronic markets and craftsman workshops to assembly lines and design solution houses, Shenzhen immerses technology designers in a mode of prototyping that is tied to the feel and touch of materials as well as the concrete processes of manufacturing. Many of the people we interviewed agreed that "being in it" was crucial to learning, understanding, and working with what they considered to be an open, informal and highly professionalized design practice.

The goal of this paper has been to critically unpack contemporary maker discourse by examining the remake of Shenzhen. In so doing, we question the imaginary of Shenzhen as the "Silicon Valley for Hardware," that has been fueled by promotional campaigns of hardware incubators and corporate investment in the region. These often linear stories of progress, which assume that Shenzhen is "catching up" with innovation centers like Silicon Valley, tend to be void of the intricacies of the region's production processes described in this paper; from its history of outsourcing and piracy to the global scale of contemporary shanzhai production. We have shown that innovation, design and production are necessarily situated, evolving in close relation to particular histories of technological, economic and social development. In this, the paper follows the call to locate design $[9,23,25,46]$ so as to include the site of industrial production itself. Efforts in critical computing have long called upon researchers and designers to reflect upon "the values, attitudes, and ways of looking at the world that we are unconsciously building into our technologies" as well as the "values, practices and 
experiences that are unconsciously, but systematically left out" [42].

Clearly this extends well beyond the common user-designer relationship. What values, norms and attitudes towards manufacturing and production do we consciously or unconsciously build not just into our designs, but also into our critical theories and practices? What new possibilities are opened up if we take seriously diverse and distributed cultures of production? Who is considered a legitimate participant in the "maker" revamp of industrial production? What expertise and work is rendered invisible as makers turn visions of networked objects into mass-produced artifacts? These questions recall the central concerns of early theorists of participatory design: a deep engagement with sites of production, labor, and manufacturing.

\section{ACKNOWLEDGMENTS}

We would like to thank everyone who contributed to this research, particularly those at Seeed Studio, Chaihuo 柴火, DFRobot, and XinCheJian 新车间, as well as all the makers, entrepreneurs, and shanzhai producers, who shared with us their time and insights. This research was in part funded by the National Science Foundation (under award \#1321065), the Lieberthal-Rogel Center for Chinese Studies, and the Intel Science and Technology Center for Social Computing.

\section{REFERENCES}

1. Anderson, C. 2012. Makers. The New Industrial Revolution. Crown Publishing Group, New York.

2. Ames, M., Bardzell, J., Bardzell, S., Lindtner, S., Mellis, D. and Rosner, D. Making Cultures: Empowerment, Participation, and Democracy - or Not? In Proc. Panel at CHI'14, ACM Press (2014).Anderson, C. Makers: the new industrial revolution. Random House, 2012.

3. Bannon, L. and Ehn, P. 2012. Design Matters in Participatory Design. In: J. Simonsen and T. Robertson (eds) Routledge Handbook of Participatory Design, pp. 37-63.

4. Bardzell, J. and Bardzell, S. 2013. What is "Critical" about Critical Design. ACM Conf. Human Factors in Computing Systems CHI 2013 (Paris, France), pp. 3297-3306.

5. Bardzell, J., Bardzell, S., and Hansen, L.K. 2015. Immodest Proposals: Research Through Design and Knowledge. Proc. of ACM Conference Human Factors in Computing Systems CHI'15 (Seoul, South Korea).

6. Beck, E. 2002. P for Political: Participation is Not Enough. Scandinavian journal of Information Systems, 14 (1), pp. 77-92.

7. Bødker, S. 1996. Creating Conditions for Participation Conflicts and Resources in Systems Development. Human-Computer Interaction, (11:3), pp. 215-236.
8. Boellstorff, T. 2008. The coming of age in Second Life: an anthropologist explores the virtually human. Princeton University Press.

9. Cartier, C. 2002. Transnational Urbanism in the Reform-era Chinese city: Landscapes from Shenzhen. Urban Studies 39: 1513-1532.

10. Chan, A. Networking Peripheries: Technological Futures and the Myth of Digital Universalism. MIT Press (2014).

11. Clarke, A. 2005. Situational Analysis: Grounded Theory after the Postmodern Turn. SAGE Publications.

12. Dourish, P. 2001. Where the Action Is. The Foundations of Embodied Interaction. MIT Press.

13. Dourish, P. and Mainwaring, S.D., "Ubicomp's Colonial Impulse," Proc. of UbiComp'12, Springer (2012), 133142.

14. Du, J. Shenzhen: Urban Myth of a New Chinese City. Journal of Architectural Education, Volume 63, Issue 2, pp.65-66.

15. Factory in a day. http://www.factory-in-a-day.eu/

16. Greenspan, A., Lindtner, S., Li, D. 2015. Atlantic

17. Hartman, B., Doorley, S., Klemmer, S. Hacking, Mashing, Gluing: Understanding Opportunistic Design. IEEE Journal of Pervasive Computing, 2008, Vol. 7, No. 3 , pp. 46-54.

18. Hertz. G. 2013. Critical Making. http://conceptlab.com/criticalmaking/ Last accessed September 2014.

19. Ho, J. 2010. Shanzhai: Economic/Cultural Production through the Cracks of Globalization. Crossroads: Cultural Studies Conference.

20. Houston, L. Inventive Infrastructure: An Exploration of Mobile Phone, Dissertation: Lancaster University, 2014.

21. Huang, B. 2013. The $\$ 12$ Gongkai Phone. http://www.bunniestudios.com/blog/?p=3040, last accessed September 2014.

22. Intel Newsroom. 2014. Intel CEO outlines new computing opportunities, investments and collaborations with burgeoning China Technology Ecosystem. http://newsroom.intel.com/community/intel_newsroom/ blog/2014/04/01/ last accessed June 3, 2015.

23. Irani, L., Vertesi, J., Dourish, P., Philip, K., and Grinter, R. 2010. Postcolonial Computing: A Lens on Design and Development. Proc. ACM Conf. Human Factors in Computing Systems CHI 2010 (Atlanta, GA), 13111320.

24. Ito, J. 2014. Shenzhen trip report - visiting the world's manufacturing ecosystem. LinkedIn Pulse. https://www.linkedin.com/pulse/article/2014081706093 6-1391 last accessed September 2014. 
25. Jackson, S.J., Pompe, A. and Krieshok, G. Repair worlds: maintenance, repair, and ICT for development in rural Namibia. In Proc. the ACM 2012 conference on Computer Supported Cooperative Work (CSCW 2012), ACM Press (2012), 107-116.

26. Jefferey, L. 2014. Mining Innovation from an Unexpected Source: Lessons from the Shanzhai. Lecture at the Shenzhen Maker Faire, 2014.

27. Kensing, F. and Blomberg, J. 1998. Participatory Design: Issues and Concerns. Computer Supported Cooperative Work (7:3-4), pp. 167-185.

28. Norman, D. and Klemmer, D. 2014. State of Design: How Design Education must change. LinkedIn Pulse. https://www.linkedin.com/pulse/article/2014032510243 8-12181762.

29.Lindtner, S., Hertz, G., Dourish, P. 2014. Emerging Sites of HCI Innovation: Hackerspaces, Hardware Startups, Incubators. In Proc. of the ACM SIGCHI Conference on Human Factors in Computing Systems CHI'14 (Toronto, Canada), pp.439-448.

30. Luethje, B., Huertgen, St., Pawlicki, P. and Stroll, M. 2013. From Silicon Valley to Shenzhen. Global Production and work in the IT industry. Rowman \& Littlefield Publishers.

31. Mellis, D.A. and Buechley, L. Do-it-yourself cellphones: an investigation into the possibilities and limits of high-tech diy. In Proc. the 32nd annual ACM conference on Human factors in computing systems (CHI 2014), ACM Press (2014), 1723-1732.

32. Milian, M. The Sticky Situation that delayed the Pebble Smartwatch. Global Tech, Bloomberg, Sep 16, 2013.

33. Nguyen, Josef. MAKE Magazine and the Gendered Domestication of DIY Science. Currently under the review for: Perspectives on Science.

34. O'Donnell, M-A. 2010. What exactly is an urban village anyway? http://shenzhennoted.com/2010/03/19/whatexactly-is-an-urban-village-anyway/ last accessed June $1,2015$.

35. O’Donnell, M-A. 2011. Utopian Shenzhen 1978-1982. http://shenzhennoted.com/2011/08/27/utopianshenzhen-1978-1982/ last accessed June 1, 2015.

36. Office of the Press Secretary, the White House (2013). Remarks by the President in the State of the Union Address. (http://www.whitehouse.gov/the-pressoffice/2013/02/12/remarks-president-state-unionaddress).

37. Office of the Press Secretary, the White House (2012). Remarks by the President on manufacturing and the economy. (http://www.whitehouse.gov/the-press- office/2012/03/09/remarks-president-manufacturingand-economy)

38. Philip, K., Irani, L., and Dourish, P. 2012. Postcolonial Computing: A Tactical Survey. Science, Technology, and Human Values. 37(1), 3-29.

39. Rosner, D. and Ames, M. 2014. Designing for repair?: infrastructures and materialities of breakdown. In Proc. the 17th ACM conference on Computer supported cooperative work and social computing, 319-331.

40. Rosner, D. Making Citizens, Reassembling Devices: On Gender and the Development of Contemporary Public Sites of Repair in Northern California. Public Culture 26, 172 (2014), 51-77.

41. Saxenian, A. Regional Advantage: Culture and Competition in Silicon Valley. Harvard University Press 1996.

42. Sengers, P., Boehner, K., David, S., Kaye, J. 2005. Reflective Design. AARHUS'05, pp.49-58.

43. Shapiro, D. 2005. Participatory Design: the will to succeed. AARHUS'05, p.29-38.

44. Sivek, S.C. "We Need a Showing of All Hands" Technological Utopianism in MAKE Magazine. Journal of Communication Inquiry 35, 3 (2011), 187-209.

45. Söderberg, J. 2013. Automating Amateurs in the 3D printing community: connecting the dots between 'deskilling' and 'user-friendliness.' Work organization, labour and globalization, vol 7, no. 1, pp. 124-139.

46. Suchman, L. 2002. Located Accountabilities in technology production. Scandinavian Journal of Information Systems, 14 (2): 91 - 105.

47. Turner, F. 2006. From Counterculture to Cyberculture: Stewart Brand, the Whole Earth Catalogue, and the Rise of Digital Utopianism. Chicago: University of Chicago Press.

48. Wallis, C. and Qiu, J. 2012. Shanzhaiji and the Transformation of the Local Mediascape of Shenzhen. In Sun, W. and Chio, J. (eds). 2012. Mapping Media in China, pp. 109-125, London: United Kingdom: Routlege.

49. Williams, A. and Nadeau, B. 2014. Manufacturing for Makers: From Prototype to Product. Interactions XXI, Nov-Dec 16, p.64.

50. Wong, W.W.Y. Van Gough on Demand: China and the Ready Made. University of Chicagor Press, 2014.

51.Zimmerman, J., Forlizzi, J., Evenson, S. 2007. Research through design as a method for interaction design in HCI. In Proc. of the SIGCHI Conference on Human Factors in Computing Systems, pp. 493-50. 